\title{
To Compare the Efficacy of Tamsulosin, Solifenacin and Combination of Both in the Treatment of Double-J Stent Related Irritative Lower Urinary Tract Symptoms and Low Back Pain
}

\section{A. H. M. Imrul Tareq ${ }^{1}$, Md. Sayedul Islam ${ }^{2}$}

Received: 10 - 06 - 2020 Accepted: $20-08-2020$ Conflicts of interest: None

Keywords: Cerebrovascular accident,Health-related quality of life, International prostate symptom score, Lower urinary tract symptoms, Percutaneous nephrolithotomy quality of life.

\begin{abstract}
Background: Stent-associated symptoms can have a significant impact on patient quality of life. Hematuria, urgency, frequency, dysuria, and both bladder and flank pain are the most prevalent symptoms related to indwelling ureteral stents. Among them irritative lower urinary tract symptoms and low back pain are more frequent. Despite the stent related symptoms, because of its importance stent is being kept in situ with varieties of medication. Several alpha-adrenergic blocker and antimuscarinic drugs are used to relief these symptoms like Tamsulosin, Solifenacin, Alphazosin etc. Both Tamsulosin and Solifenacin are not costly as use daily single dose. So combination of Tamsulosin and Solifenacin may act as a reliever of stent related symptoms and also cost effective.
\end{abstract}

Methods and materials: For this purpose, a total of 126 patients having unilateral double-J ureteral stent for 7 days with stent related irritative LUTS and low back pain were included in this study. This hospital based prospective randomized clinical trial was carried out in Urology department of Bangabandhu Sheikh Mujib Medical University, Dhaka, during January 2014 to June 2015, to compare the irritative IPSS, improvement of quality of life score component of IPSS, the low back pain score for double-J ureteral stent using Tamsulosin, Solifenacin and combination of both (Tamsulosin and Solifenacin)..

Results: Regarding the irritative sub group of International Prostate Symptom Score (IPSS) was observed during $2 n d$ and 4 th weeks follow up IPSS was significantly $(p<0.05)$ higher in solifenacin and Tamsulosin group with compared to Tamsulosin+Solifenacin group.

During 4th weeks follow up the mean quality of life (QOL) score was significantly $(p<0.05)$ higher in solifenacin group and Tamsulosin group with compared to Tamsulosin+Solifenacin group.During 2 nd weeks and 4 th weeks follow up visual Analogue Pain Scale $(V A P S)$ was significantly $(p<0.05)$ higher in solifenacin group followed by Tamsulosin group and Tamsulosin+Solifenacin group.

Conclusion: Combined use of Tamsulosin and Solifenacin is more effective than use of single drug (either Tamsulosin or Solifenacin) in the treatment of ureteral double-J stent related irritative LUTS and low back pain.

1. Assistant Registrar, Department of Urology, National Institute of Kidney Diseases \& Urology, Dhaka

2. Associate Professor, Department of Urology, Bangabandhu Sheikh Mujib Medical University, Shahbag Dhaka, Bangladesh Correspondence: Dr. A. H. M. Imrul Tareq, Assistant Registrar, Department of Urology, NIKDU, Dhaka, Email: imrul.tareq3 @gmail.com 


\section{Introduction}

Ureteral stents are one of the most common device used by the Urologists. One of the most preferred stents is the double-j stent with $\mathrm{j}$-shaped ends on both sides. The duration of keeping the stent in situ may differ according to the reason of the application and the experience of the urologist. (Kuyumcuoglu et al. 2012).

Some of the patient might encounter stent related morbidities, among them irritative lower urinary tract symptoms (LUTS), stent related low back pain are most frequent (Lee et al. 2013). There are several oral agents such as alpha-1-blockers and antimuscarinics available to relieve irritative LUTS and low back pain associated with ureteral double-J stents.

In the present study evaluation was done about the effectiveness of alpha-1-blocker (Tamsulosin), antimuscarinic (Solifenacin), and combination of both medications in reducing ureteral double-J stent-related irritative LUTS and low back pain using the irritative sub group of International Prostate Symptom Score (IPSSs), quality of life component of the IPSS (IPSS/ Qol) and Visual Analogue Pain Scale (VAPS) questionnaire.

The IPSS (Irritative) questionnaire consists of three questions relating to storage (irritative) symptoms and those symptoms are frequency, urgency and nocturia. Responses were graded on a five-point rating scale. The maximum scores for storage symptoms is 15 . The higher the score, the worse are the symptoms (McConnell, 1994).Visual analogue pain scale (VAPS) is a linear scale by which we can measure the degree of pain.

\section{Objectives}

General Objective:

To compare the effect of Tamsulosin, Solifenacin and combination of both medications for the treatment for double-J ureteral stent related irritative LUTS and low back pain.

\section{Specific objectives:}

To compare the occurrence of irritative LUTS (frequency, urgency and nocturia) for double-J ureteral stent after using Tamsulosin, Solifenacin and combination of both.

To compare the improvement of quality of life score component of International Prostatic Symptom Score and pain score for double-J ureteral stent according to Visual Analogue Pain Scale after using Tamsulosin, Solifenacin and combination of both.

\section{Methods and materials}

For this purpose, a total of 126 patients having unilateral double-J ureteral stent for 7 days with stent related irritative LUTS and low back pain were included in this study. This hospital based prospective randomized clinical trial was carried out in Urology department of Bangabandhu Sheikh Mujib Medical University, Dhaka, during January 2014 to June 2015, to compare the irritative IPSS, improvement of quality of life score component of IPSS, the low back pain score for double-J ureteral stent using Tamsulosin, Solifenacin and combination of both (Tamsulosin and Solifenacin)..

Patients (with post double-J ureteral stent related irritative LUTS and low back pain) are randomly allocated into 3 groups by lottery and starts Tamsulosin $0.4 \mathrm{mg}$ OD, Solifenacin 5mg OD and combination of both (Tamsulosin and Solifenacin) onwards from $8^{\text {th }}$ post operative day. All of them are followed up on $2^{\text {nd }}$ and 4 th post operative week for irritative LUTS by IPSS(irritative), quality of life by quality of life component of the IPSS (IPSS/Qol)and low back pain by Visual Analogue Pain Scale (VAPS) questionnaire.

\section{Results}

The mean age was found 29.0 \pm 7.0 years and more than a half $(54.0 \%)$ of the patients belonged to age $<30$ years. Male to female ratio was 1:1.2. Almost one third (32.2\%) patients were housewives followed by $34(27.0 \%)$ were service holder, 19(15.1\%) were student, 18(14.3\%) were other occupational status and $14(11.1 \%)$ were businessmen.More than one third (34.9\%) patients underwent ureterorenoscopy+ICPL operation and $41(32.5 \%)$ ureterolithotomy and 23(18.3\%) underwent PCNL.

Regarding the irritative sub group of International Prostate Symptom Score (IPSS) was observed during $2^{\text {nd }}$ and $4^{\text {th }}$ weeks follow up IPSS was significantly $(p<0.05)$ higher in solifenacin and Tamsulosin group with compared to Tamsulosin+ Solifenacin group.

During $4^{\text {th }}$ weeks follow up the mean quality of life (QOL) score was significantly $(\mathrm{p}<0.05)$ higher in solifenacin group and Tamsulosin group with compared to Tamsulosin+Solifenacin group.

During $2^{\text {nd }}$ weeks and $4^{\text {th }}$ weeks follow up visual Analogue Pain Scale (VAPS) was significantly ( $<<0.05)$ higher in solifenacin group followed by Tamsulosin group and Tamsulosin+Solifenacin group. 
To Compare the Efficacy of Tamsulosin, Solifenacin and Combination of Both in the Treatment of Double-J Stent

Table-I : Comparison of the IPSS score for ureteral Double-J stent after using Tamsulosin, Solifenacin and combination (of both) in $4^{\text {th }}$ week follow up ( $n=117$ )

\begin{tabular}{|c|c|c|c|c|c|c|c|}
\hline \multirow{3}{*}{$\begin{array}{l}\text { International Prostate } \\
\text { Symptom Score (IPSS) }\end{array}$} & \multicolumn{6}{|c|}{ Drug } & \multirow{3}{*}{$\begin{array}{c}\mathrm{P} \\
\text { value }\end{array}$} \\
\hline & \multicolumn{2}{|c|}{ Tamsulosin $(n=39)$} & \multicolumn{2}{|c|}{ Solifenacin $(n=40)$} & \multicolumn{2}{|c|}{ Tamsulosin+ Solifenacin $(\mathrm{n}=38)$} & \\
\hline & $\mathrm{n}$ & $\%$ & $\mathrm{~N}$ & $\%$ & $\mathrm{~N}$ & $\%$ & \\
\hline$\overline{d^{\prime \prime} 5}$ & 35 & 89.7 & 34 & 85.0 & 38 & 100.0 & \\
\hline$>5$ & 4 & 10.3 & 6 & 15.0 & 0 & 0.0 & \\
\hline Mean $\pm S D$ & \multicolumn{2}{|c|}{$3.2 \pm 1.5$} & \multicolumn{2}{|c|}{$3.2 \pm 1.9$} & \multicolumn{2}{|c|}{$0.5 \pm 0.9$} & $0.001^{\mathrm{s}}$ \\
\hline Range (min-max) & \multicolumn{2}{|c|}{$0-6$} & \multicolumn{2}{|c|}{$0-4$} & \multicolumn{2}{|c|}{$0-7$} & \\
\hline
\end{tabular}

$\mathrm{s}=$ significant; $\mathrm{P}$ value reached from ANOVA test

Table-II : Comparison of the improvement of quality of life (QOL) score after using Tamsulosin, Solifenacin and combination (of both) in $4^{\text {th }}$ week follow up $(n=117)$

\begin{tabular}{|c|c|c|c|c|c|c|c|}
\hline \multirow{3}{*}{$\begin{array}{l}\text { Quality of life } \\
\text { (QOL) score }\end{array}$} & \multicolumn{6}{|c|}{ Drug } & \multirow{3}{*}{$\begin{array}{c}\mathrm{P} \\
\text { value }\end{array}$} \\
\hline & \multicolumn{2}{|c|}{ Tamsulosin $(n=39)$} & \multicolumn{2}{|c|}{ Solifenacin $(n=40)$} & \multicolumn{2}{|c|}{ Tamsulosin+ Solifenacin $(\mathrm{n}=38)$} & \\
\hline & $\mathrm{n}$ & $\%$ & $\mathrm{~N}$ & $\%$ & $\mathrm{~N}$ & $\%$ & \\
\hline$\overline{0-1}$ & 11 & 28.2 & 14 & 35.0 & 35 & 92.1 & \\
\hline $2-3$ & 28 & 71.8 & 26 & 65.0 & 3 & 7.9 & \\
\hline Mean \pm SD & \multicolumn{2}{|c|}{$1.7 \pm 0.8$} & \multicolumn{2}{|c|}{$1.7 \pm 0.8$} & \multicolumn{2}{|c|}{$0.5 \pm 0.7$} & $0.001^{\mathrm{s}}$ \\
\hline Range (min-max) & \multicolumn{2}{|c|}{$0-3$} & \multicolumn{2}{|c|}{$0-3$} & \multicolumn{2}{|c|}{$0-3$} & \\
\hline
\end{tabular}

s=significant

$P$ value reached from ANOVA test

Table-III : Comparison of the low back pain for ureteral Double-J stent according to Visual Analogue Pain Scale (VAPS) after using Tamsulosin, Solifenacin and combination of both in $4^{\text {th }}$ weeks follow up $(n=117)$

\begin{tabular}{|c|c|c|c|c|c|c|c|}
\hline \multirow[t]{3}{*}{$\overline{\text { VAPS }}$} & \multicolumn{6}{|c|}{ Drug } & \multirow{3}{*}{$\begin{array}{c}\mathrm{P} \\
\text { value }\end{array}$} \\
\hline & \multicolumn{2}{|c|}{ Tamsulosin $(n=39)$} & \multicolumn{2}{|c|}{ Solifenacin $(n=40)$} & \multicolumn{2}{|c|}{ Tamsulosin+ Solifenacin $(\mathrm{n}=38)$} & \\
\hline & $\mathrm{n}$ & $\%$ & $\mathrm{~N}$ & $\%$ & $\mathrm{~N}$ & $\%$ & \\
\hline $\mathrm{d}^{\prime \prime} 5$ & 36 & 92.3 & 34 & 85.0 & 38 & 100.0 & \\
\hline$>5$ & 3 & 7.7 & 6 & 15.0 & 0 & 0.0 & \\
\hline Mean \pm SD & \multicolumn{2}{|c|}{$3.79 \pm 1.32$} & \multicolumn{2}{|c|}{$4.28 \pm 1.41$} & \multicolumn{2}{|c|}{$1.39 \pm 0.86$} & $0.001^{\mathrm{s}}$ \\
\hline Range (min-max) & \multicolumn{2}{|c|}{$1-6$} & \multicolumn{2}{|c|}{$1-10$} & \multicolumn{2}{|c|}{$1-5$} & \\
\hline
\end{tabular}

s=significant

$P$ value reached from ANOVA test

At $4^{\text {th }}$ weeks follow up mean IPSS was found $3.2 \pm 1.5$ in Tamsulosin group, $3.2 \pm 1.9$ in Solifenacin group and $0.5 \pm 0.9$ in Tamsulosin+Solifenacin group. In $4^{\text {th }}$ weeks follow up mean IPSS was significantly $(p<0.05)$ lower in Tamsulosin+Solifenacin group than Tamsulosin and Solifenacin group.

At $4^{\text {th }}$ weeks follow up mean QOL was found $1.7 \pm 0.8$ in Tamsulosin group, $1.7 \pm 0.8$ in Solifenacin group and
$0.5 \pm 0.7$ in Tamsulosin+Solifenacin group. In $4^{\text {th }}$ weeks follow up mean QOL was significantly $(p<0.05)$ lower in Tamsulosin+Solifenacin group than Tamsulosin and Solifenacin group.

At $4^{\text {th }}$ weeks follow up mean VAPS was found $3.79 \pm 1.32$ in Tamsulosin group, $4.28 \pm 1.41$ in Solifenacin group and $1.39 \pm 0.86$ in Tamsulosin+ Solifenacin group. In $4^{\text {th }}$ weeks follow up mean VAPS was significantly 
$(p<0.05)$ lower in Tamsulosin+ Solifenacin group than Tamsulosin and Solifenacin group.

\section{Conclusion}

Combination therapy with Tamsulosin and Solifenacin should be strongly considered then single use of either drug for patients who complaint of double-J stentrelated irritative lower urinary symptoms and low back pain. In the future, large-scale, prospective, and randomized study will be needed.

\section{Limitation of study}

1. The study was conducted in a single centre and small sample size. So that the results of the study may not be reflect the exact picture of the country.

2. Lack of patients homogeneity (patient with different urologic procedures).

3. Only one type of stent was used in present study.

4. Other double-J stent related complication should consider.

\section{References}

1. Damiano, R, Autorino, R, De Sio, M, Giacobbe, A, Palumbo, IM and D' Armiento, M 2008, 'Effect of tamsulosin in preventing ureteral stent-related morbidity: a prospective study', J Endourol, vol. 22, pp. 651-6.

2. Deliveliotis, C, Chrisofos, M, Gougousis, E, Papatsoris, A, Dellis, A and Varkarakis, IM 2006, 'Is there a role for alpha1-blockers in treating double-J stent-related symptoms?', Urology, vol. 67, no. 1, pp. 35-39, 2006.

3. Dejong Y, 2011, International Prostate Symptom Score, viewed $8^{\text {th }}$ Nov 2015, <https:// en.wikipedia.org/wiki/International_Prostate_ Symptom_Score>

4. Giannarini, G, Keeley, FX, Valent, F, Manassero, F, Mogorovich, A, Autorino, R and Selli, C 2010, 'Predictors of morbidity in patients with indwelling ureteric stents: results of a prospective study using the validated Ureteric Stent
Symptoms Questionnaire', Journal compilation, BJU international, vol. 107, pp. 648- 654

5. Kuyumcuoglu, U, Eryildirim, B, Tuncer, M, Faydaci, G, Tarhan, F and Ozgül, A 2012, 'Effectiveness of medical treatment in overcoming the ureteral double-J stent related symptoms', Cite as: Can Urol Assoc J, vol. 6, pp. E234-E237.

6. Lee, YJ, Huang, KH, Yang, HJ, Chang, HC, Chan, J, Yang, TK, 2013, 'Solifenacin improves double-J stent-related symptomsin both genders following uncomplicated ureteroscopic lithotripsy', Urolithiasis, vol. 41, pp. 247-252.

7. Lim, KT, Kim, YT, Lee, TY and Park, SY 2011, 'Effects of Tamsulosin, Solifenacin, and Combination Therapy for the Treatment of Ureteral Stent Related Discomforts', Korean J Urol, vol. 52, pp. 485-488.

8. Navanimitkul, N and Lojanapiwat, B 2010, 'Efficacy of Tamsulosin $0.4 \mathrm{mg} /$ day in Relieving Double-J Stent-Related Symptoms: A Randomized Controlled Study', Journal of International Medical Research, vol. 38, p. 1436.

9. Shalaby, E, Ahmed, A, Maarouf, A, Yahia, I, Ali, M and Ghobish, A2013, 'Randomized Controlled Trial to Compare the Safety and Efficacy of Tamsulosin, Solifenacin, and Combination of Both in Treatment of Double-J Stent-Related Lower Urinary Symptoms', Hindawi Publishing Corporation Advances in Urology, 2013, pp. 6.

10. Ugur, K., Bilal, E, Murat, T, Gokhan, F, Fatih, T and Aydin, O 2012, 'Effectiveness of medical treatment in overcoming the ureteral double-J stent related symptoms', Canadian Urological Association Journal, vol. 6, no. 6, pp. 234-237.

11. Wang, CJ, Huang, SW and Chang, CH 2009, 'Effects of specific alpha-1A/1D blocker on lower urinary tract symptoms due to double-J stent: a prospectively randomized study', Urol Res, vol. 37, pp. 147-52. 